\title{
Microstructure and Wear Properties of Fe Surface Alloyed Al Alloy 319
}

\author{
J.W. Carroll, Y. Liu and J. Mazumder \\ Center for Laser Aided Intelligent Manufacturing (CLAIM), Department of Mechanical \\ Engineering, University of Michigan, G. G. Brown Bldg., 2350 Hayward St, Ann Arbor, \\ MI, USA, 48109.
}

We have conducted extensive experiments to investigate the microstructure and mechanical properties of surface alloying of Al alloy 319 with Fe for possible automobile engine component applications [1,2]. A plasma arc spray iron coating was made using a HVOF Flame Spray Industries "Plasma Transferred Wire Arc" located at the GM research facilities. Samples were coated with 24$94 \mu \mathrm{m} \mathrm{Fe}$, followed by laser surface radiation using the Center for Laser Aided Intelligent Manufacturing (CLAIM) Trumpf $\mathrm{CO}_{2}$ laser at a beam power of $750 \mathrm{~W}$, speed of $50 \mathrm{in} / \mathrm{min}$, and a beam size of $600 \mu \mathrm{m}$. After laser radiation, the Fe layer is alloyed with the Al alloy. The Vickers hardness of the laser induced alloying zone increases with increasing iron layer thickness. The Fe coated sample shows significant reduction in mass loss in a Pin-on-Disc wear test. However, when the iron thickness increases to larger than $35 \mu \mathrm{m}$, cracks are found in the coating. The microstructure was examined by scanning electron microscope (SEM) and transmission electron microscope (TEM) to account for the observed properties.

TEM samples were prepared by microtome for large area observation and by ion milling technique for high resolution and EELS mapping. Figure 1 (a) and (b) show two examples of TEM images and diffraction patterns of sample $\mathrm{A}$ and sample $\mathrm{B}$. The electron diffraction pattern in Figure 1 (a) can be well matched to the FCC structure Al alloy while the one in Figure 1 (b) is a pattern of a compound. EDX and EELS mapping are used to analyze the composition and the morphology of second phase. The composition of the Al solid solution contains 13 at $\% \mathrm{Si}$ and $4 \mathrm{at} \% \mathrm{Fe}$ and the $\mathrm{Al}$ compound phase contains $12 \mathrm{at} \% \mathrm{Si}$ and $17 \mathrm{at} \% \mathrm{Fe}$. Figure 2 is the EELS mapping of sample A. The intensity change for $\mathrm{Fe}$ and $\mathrm{Al}$ in the two images suggests two phases. The compound phase appearing white in Figure 2 (a) has a grain size smaller than $200 \mathrm{~nm}$ and distributed near grain boundaries of $\mathrm{Al}$ solid solution. As the iron coating thickness increases to $35 \mu \mathrm{m}$ in sample $\mathrm{B}$, the compound phase grows to a grain size larger than 1000nm and occupies a volume fraction larger than $60 \%$, which is responsible for the cracking the coating layer. If $\mathrm{Si}$ is considered to substitute for $\mathrm{Al}$ the compound phase has a composition close to $\mathrm{Al}_{3} \mathrm{Fe}$. X-ray diffraction pattern of the compound phase shows some resemblance to the $\mathrm{Al}_{3} \mathrm{Fe}$ phase (Space group $\mathrm{C} 2 / \mathrm{m}$ ) but convergent beam electron diffraction (CBED) reveals no mirror symmetry in the sample. This suggests a new phase in the Al-Fe-Si system. The structure of the new phase will be discussed in detail based on HRTEM and CBED study.

\section{References}

[1] J. Carroll, Y. Liu, J. Mazumder and T.A. Perry, 20 ${ }^{\text {th }}$ Inter. Cong. ICALEO 2001,p537.

[2] Y. Liu, J. Koch, J. Mazumder and K. Shibata. Metall. and Mater. Trans. B, 25B, (1994) p 425.

[3] This research is sponsored by a contract from the General Motors Corporation. TEM work was performed at the EMAL of UM and NSF DMR-9871177 is acknowledged. 

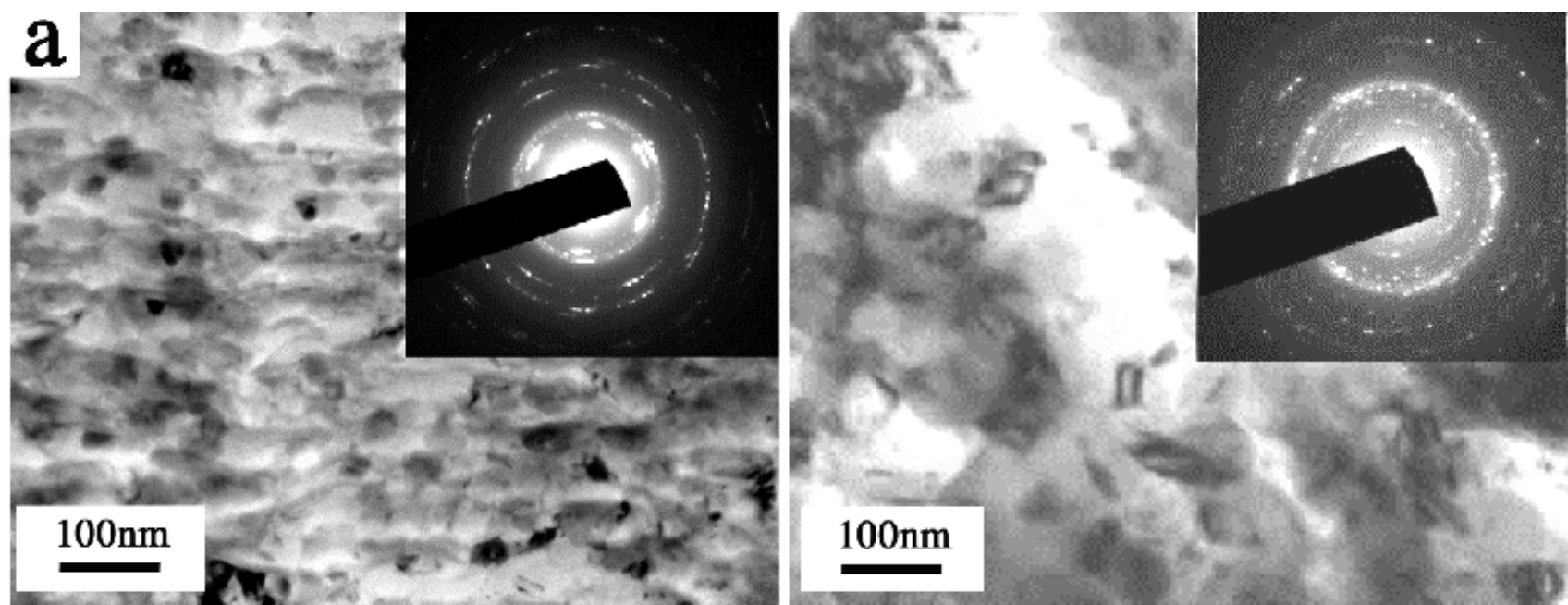

FIG. 1. TEM images of (a) sample A with a Fe coating of $28 \mu \mathrm{m}$ and (b) sample B with a Fe coating of $35 \mu \mathrm{m}$.

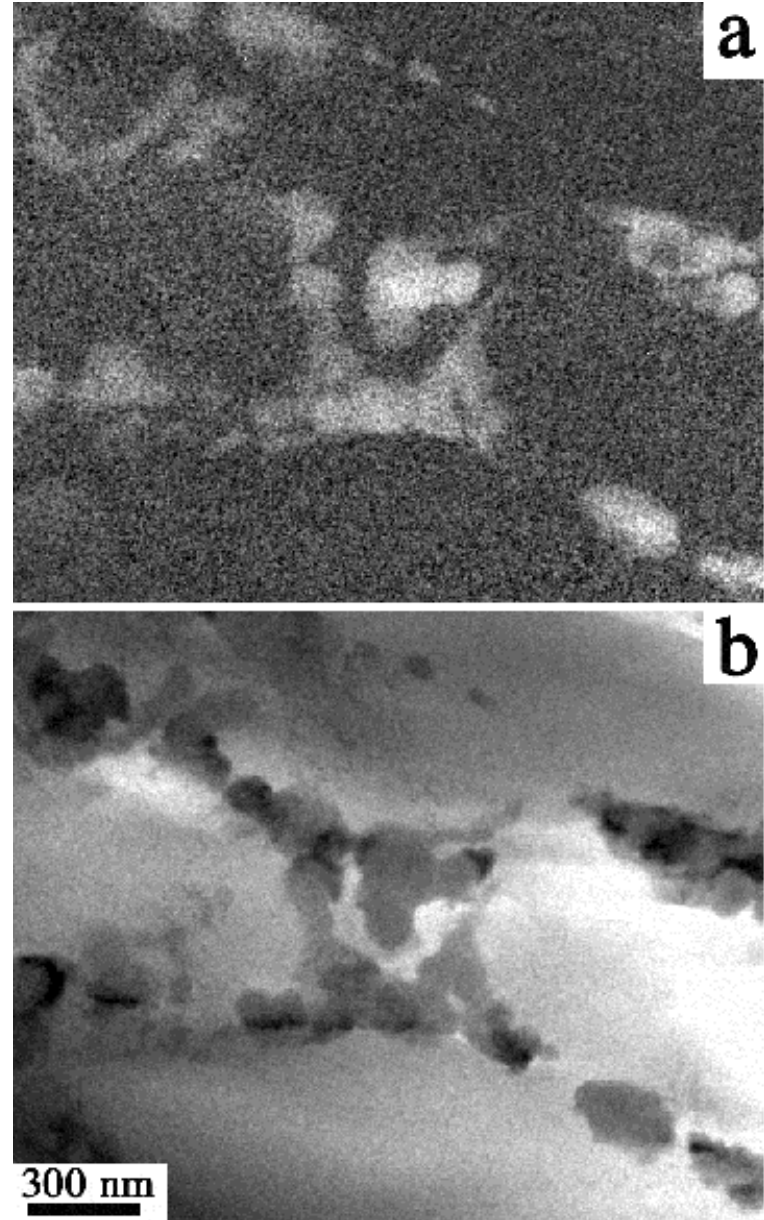

FIG. 2. EELS mapping of (a) Fe and (b) Al of sample A.
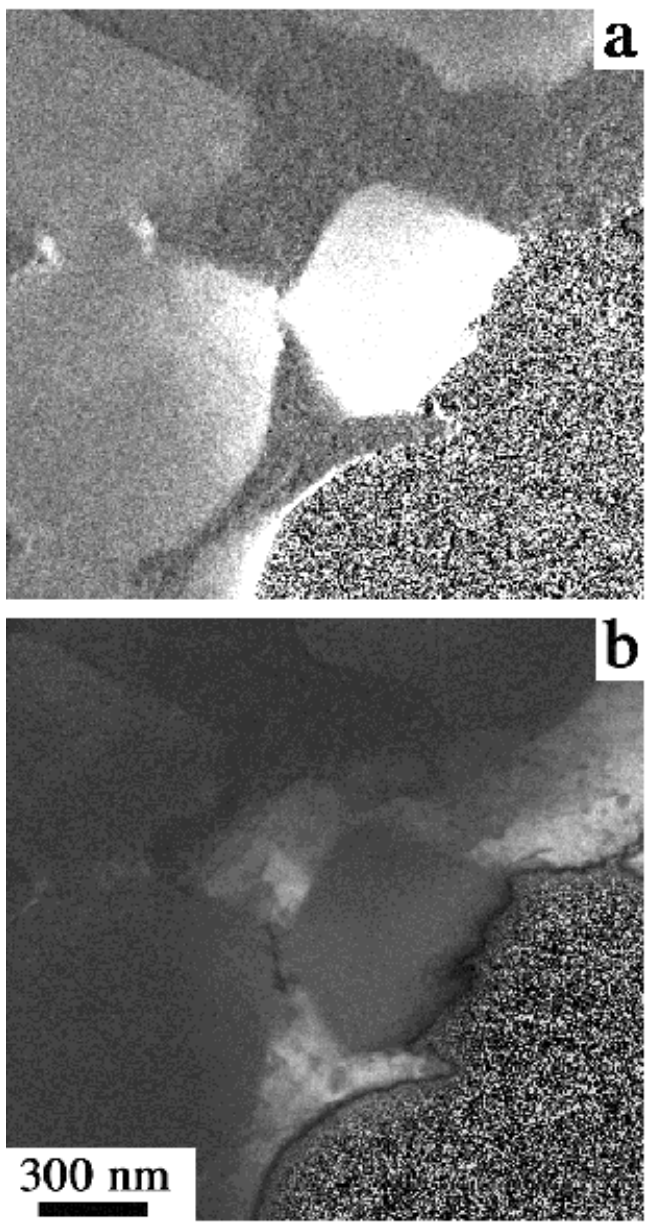

FIG. 3. EELS mapping of (a) Fe and (b) Al of sample B. 